\title{
PENGARUH KONSENTRASI ELEKTROLIT (NaCI) TERHADAP HASIL PENCELUPAN EKSTRAK DAUN ILER (Plectranthus scutellarioides L. Benth) MENGGUNAKAN MORDAN ASAM KANDIS (Garcinia xanthochymus) PADA BAHAN SUTERA
}

\author{
Siti Dahlia ${ }^{*}$, Adriani $^{2 *}$ \\ Program Studi Pendidikan Kesejahteraan Keluarga Jurusan Ilmu Kesejahteraan Keluarga \\ Fakultas Pariwisata dan Perhotelan \\ Universitas Negeri Padang \\ Jl. Prof. Dr. Hamta, Air Tawar Padang, Kel. Air Tawar Barat, Kec. Padang Utara, Kota Padang, Kode Pos 25171 \\ Sumatera Barat. Indonesia \\ Email: sitidahlia930@gmail.com.
}

\begin{abstract}
Abstrak
Penelitian ini dilatarbelakangi sebagai upaya pemanfaatan kembali zat warna alami yang ramah lingkungan pada pewarnaan tekstil untuk mengurangi bahaya penggunaan zat warna sintetis. Penelitian ini bertujuan untuk mendeskripsikan nama warna (Hue), gelap terang (Value) dan kerataan warna yang dihasilkan dari pencelupan ekstrak daun iler (Plectranthus scutellarioides L. Benth) menggunakan mordan asam kandis (Garcinia xanthochymus) pada bahan sutera dengan perbedaan konsentrasi elektrolit $(\mathrm{NaCl})$ yaitu 10 gram, 70 gram dan 130 gram. Jenis penelitian ini merupakan penelitian eksperimen. Jenis data berupa data primer. Pencelupan dengan konsentrasi $\mathrm{NaCl} 30$ gram menghasilkan nama warna Mulberry Violet, warna cukup gelap dan kerataan termasuk kategori sangat rata. Pada konsentrasi $\mathrm{NaCl} 70$ gram menghasilkan nama warna Hot Crimson, warna gelap dan kerataan termasuk kategori cukup rata. Pada konsentrasi $\mathrm{NaCl} 130$ gram menghasilkan nama warna Dark Purple, warna sangat gelap dan kerataan termasuk kategori kurang rata.
\end{abstract}

Kata Kunci: daun iler, perbedaan konsentrasi elektolit.

\begin{abstract}
The research background is an effort to reuse natural dyes that are environmentally friendly in textile coloring to reduce the danger of using synthetic dyes. This study aims to describe the color name (Hue), light darkness (Value) and color uniformity resulting from immersion of iler leaf extract (Plectranthus scutellarioides L. Benth) using kandis acid mordan (Garcinia xanthochymus) on silk material with different electrolyte concentrations $(\mathrm{NaCl})$ namely 10 grams, 70 grams and 130 grams. This type of research is experimental research. The type of data is primary data. Dyeing with 30 grams of $\mathrm{NaCl}$ concentration produced the name Mulberry Violet, the color was quite dark and the flatness was very flat. At a concentration of 70 grams, $\mathrm{NaCl}$ produces Hot Crimson color names, dark colors, and flatness including fairly flat categories. At the concentration of 130 grams of $\mathrm{NaCl}$ produces the name Dark Purple, the color is very dark and flatness is categorized as uneven.
\end{abstract}

Keywords: iler leaves, the difference of electrolyte concentration.

\section{PENDAHULUAN}

Limbah zat warna sintetis mengandung senyawa kimia yang sulit hancur didalam tanah yang menyebabkan pencemaran lingkungan dan berdampak buruk pada kesehatan manusia. Menurut Paryanto (2012:26) "Penggunaan zat pewarna sintetis yang memang terbukti lebih mudah berdampak negatif yaitu bersifat karsinogenik (menyebabkan kanker) aibat kandungan logam berat pada pewarna sintetik. Unsur logam berat pada pewarnaan sintetis seperti krom, tembaga dan seng dan juga menyebabkan penyakit kanker kulit dan kerusakan otak pada manusia".

Untuk menanggulangi dampak negatif penggunaan pewarna sintetis maka perlunya upaya utuk mengganti bahan-bahan tersebut dengan zat warna alami yang lebih ramah lingkungan. Menurut Sunaryati (2000:103) "Untuk menghindari penggunaan zat warna sintetik, perlu zat warna alternatip sebagai gantinya. Salah satunya yaitu dengan menggali 


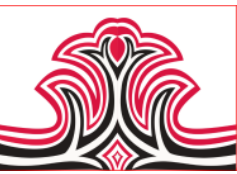

sumber kekayaan alam yang ada di negeri tercinta ini seperti tumbuh-tumbuhan".

Zat warna alam adalah zat warna ynag diperoleh dari alam seperti tumbuh-tumbuhan, bintang dan minerlaminerla yang memiliki kandungan pigmen penimbul warna. Tekstil yang diwarnai dengan zat warna alam memilki potensi pasar yang tinggi untuk memasuki pasar global dengan daya tarik pada karakteristiknya yang etnik, unik eksklusif serta lebih ramah lingkungan.

Tanaman iler atau miana (Plectranthus scutellarioides L. Benth) merupakan tanaman semak semusim yang sudah tersebar luas diseluruh dunia. Batang dan daun tanaman ini bisa dimanfaatkan sebagai pewarna alami karena mengandung tannin dan antosianin. Tumbuhan iler memiliki kandungan kimia: minya atsiri, fenol, tannin, lemak, phytosterol, kalsium oksalat, dan peptik (Tabalubun 2013:14).

Pewarnaan tekstil dengan daun iler dilakukan dengan proses pencelupan. Pencelupan adalah proses pemberian warna pada bahan tekstil secara merata dengan cara merendam bahan tekstil ke dalam larutan zat warna alam sehingga terjadi penyerapan warna.

Untuk menigkatkan afinitas zat warna alam terhadap serat tekstil dibutuhkan zat mordan. Menurut Sewan (2007:71) "Mordan adalah bahan pembantu untuk beits yaitu menimbulkan warna dari zat alam". Peneliti menggunakan mordan asam kandis yang mudah ditemukan dan ramah lingkungan. Teknik mordanting yang digunakan adalah meta-mordanting karena warna yang dihasilkan lebih bagus.

Bahan tekstil yang digunakan pada pencelupan zat warna alami sebaiknya yang berasal dari alam. Bahan tekstil dipilih yang memiliki daya serap tinggi terhadap zat pewarna alami. Pada penelitian ini menggunakan bahan sutera. Menurut Fitrihana (2007:2) "Bahan sutera memiliki afinitas paling bagus terhadap zat warna alam dibandingkan dengan bahan kapas".

Penyerapan zat warna dalam pencelupan perlu penambahan zat-zat pembantu, untuk mendorong zat warna agar lebih mudah terserap ke dalam serat tekstil. Menurut Sunarto (2008:48) “faktor-faktor yang mempengaruhi larutan celup adalah (1) Pengaruh elektrolit (2) Pengaruh suhu (3) Pengaruh perbandingan larutan celup (4) Pengaruh $\mathrm{pH}^{\prime}$. Salah satu faktor yang mempengaruhi hasil celupan adalah elektrolit. Elektrolit bisa berupa air, asam, basa atau
Gorga Jurnal Seni Rupa

Volume 08 Nomor 01 Januari-Juni 2019

p-ISSN: 2301-5942 | e-ISSN: 2580-2380

berupa senyawa kimia lainnya. Dalam penelitian ini, elektrolit yang digunakan adalah Natrium Klorida $(\mathrm{NaCl})$.

Berdasarkan hasil pra-eksperimen yang dilakukan peneliti yang dihasilkan dari pencelupan bahan sutera menggunakan ekstrak daun iler dengan mordan asam kandis dengan konsentrasi $\mathrm{NaCl} 30$ gram, 70 gram dan 130 gram menghasilkan warna yang lebih bagus yaitu red-violet . Pada penelitian ini peneliti akan melihat nama warna, gelap terang warna dan keratan warna. Penulis tertarik meneliti dengan judul "Pengaruh Konsentrasi Elektrolit $(\mathrm{NaCl})$ Terhadap Hasil Pencelupan Ekstrak Daun Iler (Plectranthus scutellarioides L. Benth) Menggunakan Mordan Asam Kandis (Garcinia xanthochymus) Pada Bahan Sutera”.

\section{KAJIAN TEORI}

Pewarnaan tekstil dilakukan dengan proses pencelupan. Menurut Chatib (1980:1) "Pencelupan yaitu proses pemberian warna pada bahan secara merata dengan bermacam-macam zat warna dan bersifat permanen".

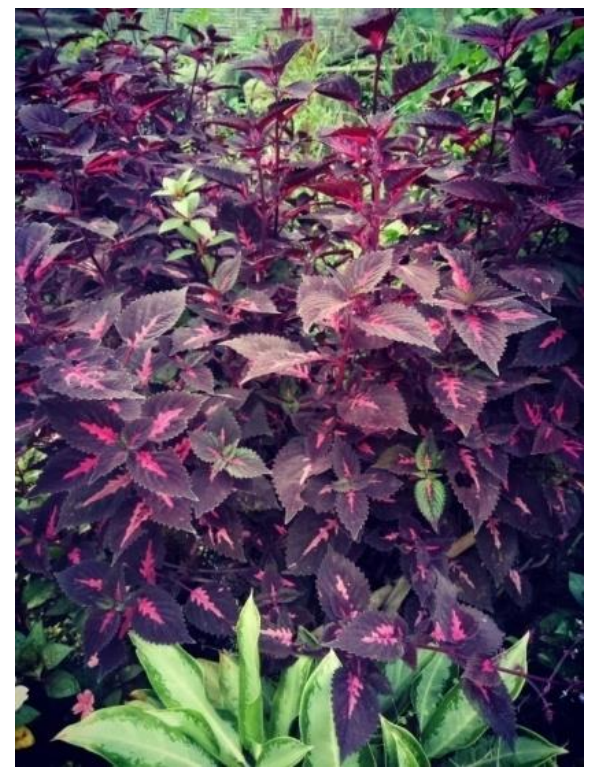

Gambar 1. Tanaman Iler (Sumber: Siti Dahlia, 2018)

Tanaman iler merupakan tanaman yang memiliki varietas warna sangat banyak. Tanaman iler mengandung senyawa tanin dan antosianin yang memberikan warna pada daun dan batang. Kandungan tanin mampu mengikat warna pada serat tekstil sehingga daun iler dapat dijadikan sebagai zat pewarna tekstil.

Elektrolit $(\mathrm{NaCl})$ merupakan salah satu faktor pendorong dalam penceupan yang berfungsi untuk 


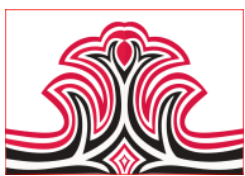

membantu penyerapan zat warna kedalam serat tekstil. Penambahan $\mathrm{NaCl}$ kedalam larutan celup dilakukan sebagai upaya untuk memperbesar jumlah zat warna alam yang terserap oleh serat.

Dalam pewarnaan juga dibutuhkan zat mordan. Mordan adalah zat yang menimbulkan, memperkuat daya serap warna dan mengurangi kelunturan pada kain. Zat mordan ada dua jenis yaitu mordan alam dan mordan kimia. Salah satu mordan alam yang bisa digunakan adalah mordan asam kandis (Garcinia xanthochymus). Pemanfaatan kulit buah asam kandis sebagai mordan dapat berupa kulit buah kering dan kulit buah segar.

Dalam proses pencelupan ada tiga cara mordanting yaitu bahan dimordan kemudian dicelup zat warna disebut pra-mordanting, bahan dicelup pada campuran zat warna alam dan zat mordan disebut simultanmordanting dan bahan dicelup zat warna terlebih dahulu kemudian dimordan disebut post-mordanting. Teknik mordanting yang digunakan yaitu simultanmordanting.

Bahan sutera merupakan serat yag diperoleh dari larva ulat sutera sewaktu membentu kepompong yang berbentuk filamen. Sutera merupakan salah satu tekstil yang berasal dari serat alam yang baik digunakan pada pencelupan dengan zat warna alam. Diantara serat alam lainnya bahan sutera memiliki afinitas yang paling bagus sehingga memudahan zat warna alami terserap dengan rata.

\section{METODE PENELITIAN}

Penelitian eksperimen ini menggunakan jenis metode penelitian True Eksperimental. Objek penelitian yang digunakan adalah bahan sutera yang telah dicelup dengan zat warna alam ekstrak daun iler (Plectranthus scutellarioides L. Benth) menggunana mordan asam kandis (Garcinia xanthochymus) dengan konsentrasi $\mathrm{NaCl} 30$ gram, 70 gram dan 130 gram.

Pada penelitian ini menggunaan ekstrak daun iler, bahan, alat, waktu dan perlakuan sama. Perbedaan terletak pada konsentrasi $\mathrm{NaCl}$ yaitu 30 gram, 70 gram dan 130 gr.

Instrumen pada penelitian ini berbentuk panduan penilaian terhadap pengaruh hasil pencelupan berupa nama warna (Hue), gelap terang warna (value) dan kerataan warna. Instrumen penelitian berupa kuisioner atau angket sebagai alat pengumpul data yang disusun menurut skala bertingkat (rating scale).
Gorga Jurnal Seni Rupa

Volume 08 Nomor 01 Januari-Juni 2019

p-ISSN: 2301-5942 | e-ISSN: 2580-2380

Dalam penelitian ini teknik analisis data disusun dalam bentuk tabel. Data diolah menggunakan program SSPS (Statistical Product and Service Solutions) untuk melihat perbedaan hasil pencelupan estrak daun iler (Plectranthus scutellarioides L. Benth) dengan mordan asam kandis (Garcinia xanthochymus) pada bahan sutera dengan konsentrasi $\mathrm{NaCl} 30$ gr, 70 gr dan 130 gr. Dalam mengolah data hasil pencelupan menggunakan uji Friedman $K$ related sample.

\section{HASIL DAN PEMBAHASAN \\ 1.Hasil}

Uji friedman $k$-related sample merupakan statistik non parametik, uji ini dilakukan jika sampel terlalu sedikit atau kurang dari 30. Hasil data penelitian gelap terang warna terhadap 19 orang panelis, diperoleh nilai mean sebagai berikut: $\mathrm{NaCl} 30$ gram mendapat rata-rata 2,21 NaCl 70 gram mendapat rata-rata 2,95 sedangkan $\mathrm{NaCl} 130$ gram mendapat rata-rata 3,32.

Tabel 1. Hasil Uji Friedman K-related Sample Gelap Terang Warna (Value) yang Dihasilkan pada Pencelupan Bahan Sutera Menggunakan Ekstrak Daun Iler dengan Mordan Asam Kandis Konsentrasi $\mathrm{NaCl} 30$ gr, 70 gr dan 130 gr.

\section{Test Statistics ${ }^{\mathrm{a}}$}

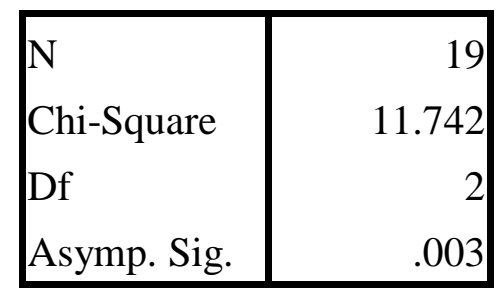

Pada tabel 1 dapat dijelaskan bahwa uji Friedman $K$ Related Sample gelap terang warna (Value) pada pencelupan bahan sutera menggunakan ekstrak daun iler (Plectranthus scutellarioides L. Benth) dengan mordan asam kandis (Garcinia xanthochymus) konsentrasi $\mathrm{NaCl} 30$ gram, 70 gram dan 130 gram diperoleh nilai signifikasi sebesar 0,003 yang lebih kecil dari taraf signifikasi 0,05 atau $0,003<0,05$.

Hasil data penelitian kerataan warna terhadap 19 panelis, diperoleh nilai mean sebagai berikut: konsentrasi $\mathrm{NaCl} 30$ gram mendapatkan rata-rata 3,26 pada konsentrasi $\mathrm{NaCl} 70$ gram 3,11 dan konsentrasi $\mathrm{NaCl} 130$ gram 2,74. 
Tabel 2. Hasil uji Friedman K-Related Sample Kerataan Warna yang Dihasilkan pada Pencelupan Bahan Sutera Menggunakan Ekstrak Daun Iler dengan Mordan Asam Kandis (penambahan $\mathrm{NaCl} 30$ gr, 70 gr dan 130 gr.

Test Statistics ${ }^{\mathrm{a}}$

\begin{tabular}{|l|r|}
\hline N & 19 \\
Chi-Square & 4.481 \\
df & 2 \\
Asymp. Sig. & .106 \\
\hline
\end{tabular}

Pada tabel 2 dapat dijelaskan bahwa uji Friedman $K$ Related Sample kerataan warna yang dihasilkan pencelupan bahan sutera menggunakan ekstrak daun iler (Plectranthus scutellarioides L. Benth) dengan mordan asam kandis (Garcinia xanthochymus) penambahan $\mathrm{NaCl} 30$ gr, 70 gr dan 130 gr diperoleh nilai signifikasi sebesar 0,106 yang lebih besar dari taraf signifikasi 0,05 atau $0,106>0,05$.

\section{Pembahasan}

Zat warna alam ekstrak daun iler pada bahan sutera menggunakan mordan asam kandis dilihat dari nama warna (Hue), gelap terang warna (Value) dan kerataan warna.

Nama warna (Hue) yang dihasilkan dari perbedaan konsentrasi $\mathrm{NaCl}$ terhadap hassil pencelupan ekstrak daun iler menggunakan mordan asam kandis pada bahan sutera dapat dilihat pada tabel berikut:

Tabel 3. Nama Warna (Hue) yang Dihasilkan dari Perbedaan Konsentrasi Natrium Klorida terhadap Hasil Pencelupan Ekstrak Daun Iler Menggunakan Mordan Asam Kandis pada Bahan Sutera.

\begin{tabular}{|c|c|c|c|c|}
\hline Pencelupan & Warna & Nama Warna & RGB & \begin{tabular}{|l|} 
Kode \\
Warna
\end{tabular} \\
\hline $\mathrm{NaCl} 30 \mathrm{gr}$ & & Mulberry Violet & $\begin{array}{l}\text { R } 177 \\
\text { G } 096 \\
\text { B } 137\end{array}$ & \#B16089 \\
\hline $\mathrm{NaCl} 70$ gr & & Hot Crimson & $\begin{array}{l}\text { R } 153 \\
\text { G } 044 \\
\text { B } 097\end{array}$ & \#992C61 \\
\hline $\mathrm{NaCl} 130 \mathrm{gr}$ & & Dark Purple & $\begin{array}{l}\text { R } 95 \\
\text { G } 30 \\
\text { B } 95\end{array}$ & \#5F1E5F \\
\hline
\end{tabular}

Sumber: Aplikasi Colorblind Assistant

Berdasarkan tabel 3 dapat dijelaskan nama warna beserta kode warna RGB (Red, Green dan Blue) yang memiliki nilai terendah 0 dan tertinggi 255. Dari hasil penelitian dijelaskan pada pencelupan bahan sutera menggunakan ekstrak daun iler (Plectranthus scutellarioides L. Benth) dengan mordan asam kandis (Garcinia xanthochymus) penambahan $\mathrm{NaCl} 30$ gram
Gorga Jurnal Seni Rupa

Volume 08 Nomor 01 Januari-Juni 2019 p-ISSN: 2301-5942 | e-ISSN: 2580-2380

menghasilkan nama warna Mulberry Violet kode warna \#B16089, memiliki nilai $\mathrm{R}$ (Red) 177 atau 69,41\% G (Green) 96 atau 37,64\% dan B (Blue) 137 atau $53,72 \%$.

Pada pencelupan bahan sutera menggunakan ekstrak daun iler (Plectranthus scutellarioides L. Benth) dengan mordan asam kandis (Garcinia xanthochymus) penambahan $\mathrm{NaCl} 70$ gram menghasilkan nama warna (Hue) Hot Crimson kode warna \#992C61 yang memiliki nilai R (Red) 153 atau 60\% G (Green) 44 atau 17,25\% dan B (Blue) 97 atau 98,04\%.

Selanjutnya pada pencelupan bahan sutera menggunakan ekstrak daun iler (Plectranthus scutellarioides L. Benth) dengan mordan asam kandis (Garcinia xanthochymus) penambahan $\mathrm{NaCl} 130$ gram menghasilkan nama warna (Hue) Dark purple kode warna \#5F1E5F yang memiliki nilai $\mathrm{R}$ (Red) 95 atau 37,25\% G (Green) 30 atau 11,76\% dan B (Blue) 95 atau $37,25 \%$.

Daun iler (Plectranthus scutellarioides L. Benth) merupakan salah satu tumbuhan yang mengandung Antosianin dan Tanin. Antosianin merupakan pigmen yang membentuk warna pada tanaman. Menurut Ervira (2013:2) bahwa "Antosianin merupakan pigmen yang larut dalam air memberikan warna biru, ungu, kuning, violet, magenta, merah dan orange". Selain itu daun iler (Plectranthus scutellarioides L. Benth) juga mengandung tanin. Tanin dalam pencelupan bermanfaat sebgai bahan pewarna dan perekat zat warna pada kain.

Berdasarkan hasil pencelupan pada bahan sutera menggunakan ekstrak daun iler (Plectranthus scutellarioides L. Benth) dengan mordan asam kandis (Garcinia xanthochymus) dengan konsentrasi $\mathrm{NaCl} 30$ gram 52,63\% panelis menyatakan cukup gelap, pencelupan bahan sutera menggunakan ekstrak daun iler (Plectranthus scutellarioides L. Benth) dengan mordan asam kandis (Garcinia xanthochymus) dengan konsentrasi $\mathrm{NaCl} 70$ gram $63,15 \%$ panelis menyatakan gelap dan pencelupan bahan sutera menggunakan ekstrak daun iler (Plectranthus scutellarioides L. Benth) dengan mordan asam kandis (Garcinia xanthochymus) dengan konsentrasi $\mathrm{NaCl} 130$ gram $57,89 \%$ panelis menyatakan sangat gelap.

Berdasarkan hasil pencelupan bahan sutera menggunakan ekstrak Daun Iler (Plectranthus scutellarioides L. Benth) dengan mordan asam kandis (Garcinia xanthochymus) penamabahan $\mathrm{NaCl} 30$ gram $47,36 \%$ panelis menyatakan sangat rata, penambahan 
$\mathrm{NaCl} 70$ gram 36,84\% panelis menyatakan cukup rata dan $36,84 \%$ panelis menyatakan kurang rata.

Berdasarkan uraian diatas dapat diambil kesimpulan bahwa pada pencelupan bahan sutera menggunakan ekstrak daun iler (Plectranthus scutellarioides L. Benth) dengan mordan asam kandis menghasilkan kerataan warna yang berbeda. Jadi semakin banyak $\mathrm{NaCl}$ yang ditambahkan maka kerataan warna yang dihasilkan kurang rata.

Berdasarkan analisis yang diperoleh dari uji Friedman K-Related Sample untuk gelap terang warna (Value) data yang diperoleh dari pencelupan bahan sutera menggunakan ekstrak daun iler (Plectranthus scutellarioides L. Benth) konsentrasi $\mathrm{NaCl} 30$ gram, 70 gram dan 130 gram adalah 0,003 yang lebih kecil dari taraf signifikasi sebesar 0,05 atau $0,003<0,05$ artinya $H_{0}$ di tolak. Dari penjelasan diatas dapat diambil kesimpulan bahwa terdapat perbedaan yang signifikan akibat penambahan $\mathrm{NaCl} 30$ gram, 70 gram dan 130 gram terhadap gelap terang warna (Value) dalam pencelupan bahan sutera menggunakan ekstrak daun iler (Plectranthu scutellarioides L. Benth) dengan mordan asam kandis (Garcinia xanthochymus).

Berdasarkan analisis yang diperoleh dari uji Friedman $K$-Related Sample untuk kerataan warna data yang diperoleh dari pencelupan bahan sutera menggunakan ekstrak daun iler (Plectranthus scutellarioides L. Benth) konsentrasi $\mathrm{NaCl} 30$ gram, 70 gram dan 130 gram adalah 0,106 yang lebih besar dari taraf signifikasi 0,05 atau $0,106>0,05$ yang artinya $H_{0}$ diterima. Dari penjelasan diatas dapat diambil kesimpulan bahwa tidak terdapat perbedaan yang signifikan akibat penambahan $\mathrm{NaCl} 30$ gr, 70 gr dan 130 gr pada pencelupan bahan sutera menggunakan ekstrak daun iler (Plectranthus scutellrioides L. Benth) dengan mordan asam kandis (Garcinia xanthochymus) terhadap kerataan warna.

\section{KESIMPULAN DAN SARAN \\ 1.Kesimpulan}

\section{1). Nama Warna (Hue)}

Nama warna (Hue) pada pencelupan bahan sutera menggunakan ekstrak daun iler (Plectranthus scutellarioides L. Benth) dengan mordan asam kandis (Garcinia xanthochymus) penambahan $\mathrm{NaCl} 30$ gram menghasilkan nama warna Mulberry Violet kode warna \#B16089, penambahan $\mathrm{NaCl} 70$ gram menghasilkan nama warna (Hue) Hot Crimson kode warna \#992C61 dan penambahan $\mathrm{NaCl} 130$ gram
Gorga Jurnal Seni Rupa

Volume 08 Nomor 01 Januari-Juni 2019

p-ISSN: 2301-5942 | e-ISSN: 2580-2380

menghasilkan nama warna (Hue) Dark purple kode warna \#5F1E5F.

\section{2). Gelap Terang Warna (Value)}

Berdasarkan hasil pencelupan pada bahan sutera menggunakan ekstrak daun iler (Plectranthus scutellarioides L. Benth) dengan mordan asam kandis (Garcinia xanthochymus) dengan konsentrasi $\mathrm{NaCl} 30$ gram 52,63\% panelis menyatakan cukup gelap, dengan konsentrasi $\mathrm{NaCl} 70$ gram 63,15\% panelis menyatakan gelap dan pada konsentrasi $\mathrm{NaCl} 130$ gram $57,89 \%$ panelis menyatakan sangat gelap.

\section{3). Kerataan Warna}

Berdasarkan hasil pencelupan bahan sutera menggunakan ekstrak Daun Iler (Plectranthus scutellarioides L. Benth) dengan mordan asam kandis (Garcinia xanthochymus) penambahan $\mathrm{NaCl} 30$ gram $47,36 \%$ panelis menyatakan sangat rata, penambahan $\mathrm{NaCl} 70$ gram 36,84\% panelis menyatakan cukup rata dan $36,84 \%$ panelis menyatakan kurang rata.

\section{Saran}

Dengan penelitian ini diharapkan Jurusan PKK FPP UNP dapat melengkapi peralatan yang digunakan, contohya alat pengukur warna tekstil supaya penelitian eksperimen untuk kedepannya lebih berkembang.

Dengan adanya penelitian ini diharapkan Jurusan Ilmu Kesejahteraan Keluarga Program Studi Pendidikan Kesejahteraan Keluarga (Tata Busana) dapat mengembangkan pengetahuan dan keterampilan dalam pewarnaan zat warna alami

Dengan adanya penelitian ini diharapkan masyarakat dapat melestarikan tanaman iler (Plectranthus scutellarioides L. Benth) dan mengoptimalkan pemanfaatannya untuk pewarnaan tekstil.

\section{DAFTAR RUJUKAN}

Chatib, Winarni. (1980). Teori Penyempurnaan Tekstil 2. Jakarta: Direktorat Pendidikan Menengah Kejuruan.

Ervira, Desty. (2013). The Miracle Of Fruits. Jakarta: Agro Media Pustaka.

Fitrihana, Noor. (2007). Teknik Eksplorasi Zat Pewarna Alam Dari Tanaman Di Sekitar Kita Untuk Pencelupan Bahan Tekstil. Yogyakarta: PKK FT UNY.

Paryanto, Purwanto (2012). Pembuatan Zat Warna Alami dalam Bentuk Serbuk untuk Mendukung Industri Batik Indonesia. Jurnal Rekayasa Proses, 6 (1), 26-29. 
Sewan, Susanto. (1973). Seni Kerajinan Batik Indonesia. Yogyakarta: Penelitian Batik \& Kerajinan.

Sunarto. (2008). Teknologi Pencelupan Dan Pencapan Jilid 2. Jakarta: Direktorat Pembinaan Sekolah Menengah Kejuruan.

Sunaryati. (2000). Pengaruh Tatacara Pencelupan Zat Warna Alam Daun Sirih Pada Hasil Pencelupan Kain Sutera. Yogyakarta:

Tabalubun. (2013). Efek Analgesik Daun Iler (Coleus atropurpureus L. Benth) Dengan Metode Rangsang Kimia Pada Mencit Betina. Skripsi. Yogyakarta: Universitas Sanata Dharma. 